\title{
Inclusión democrática e igualdad política en una Dêmoicracia europea en transformación
}

\author{
Democratic Inclusion and Political Equality \\ in the Transforming European Dêmoicracy
}

Ander Errasti Lopez

Globernance: Instituto de Gobernanza Democrática de Donostia - San Sebastián

ander.errasti.lopez@gmail.com

Sumario: I. Introducción.-II. Crisis de la democracia en Europa. - III. La importancia de la inclusión democrática y la igualdad política. -IV. La transformación dêmoicratica.-V. Conclusión.-VI. Referencias.

Resumen: Este artículo sostiene que la principal amenaza para la construcción de una Europa común tras la crisis multidimensional iniciada en el 2008 es la pérdida de estatus democrático de la ciudadanía. El artículo parte de una descripción no exhaustiva de la crisis de la democracia en Europa afirmando que, si bien tuvo por origen la crisis económica, ha tenido ecos en otras áreas. Siendo el incremento de las desigualdades un factor explicativo transversal, la causa de la crisis de la democracia no son estas desigualdades, sino su efecto: la aparición de un creciente precariado político. La segunda sección analiza en qué sentido este nuevo sujeto representa la crisis de la democracia en Europa: su exclusión del proceso de ponderación de intereses vulnera los principios básicos de igualdad política e inclusión democrática. La tercera sección plantea que, si bien la respuesta ha de ser europea, las alternativas tradicionales federal y soberanista no ofrecen la perspectiva teórica adecuada. La opción dêmoicratica, por el contrario, acepta descriptivamente la realidad como es, i.e. sin negar la existencia de hechos políticos nacionales, a la par que persiste en la aspiración normativa de continuar trabajando en común por la construcción de la democracia en Europa.

Palabras clave: dêmoicracia, precariado político, igualdad política, inclusión democrática

Abstract: The article holds that the main threat to the construction of a common Europe after the multidimensional crisis that began in 2008 is the loss of citizens' democratic status. Section I introduces a non-exhaustive description of the crisis of democracy in Europe stating that, even if it initially was an economic crisis, it has had echoes on other areas. Even if the transversal explanatory factor of this phenomena is the increase of inequalities, the cause of the crisis of European 
democracy are not these inequalities but their effect: the appearance of an increasing political precariat. Section Two focuses on analysing the sense in which this new subject represents the crisis of democracy in Europe: their exclusion from the interest weighting process violates the basic principles of political equality and democratic inclusion. Section Three proposes that, even if the answer should necessarily be European, the traditional federal and sovereigntist alternatives do not provide an adequate theoretical perspective. The dêmoicratic option, in turn, accepts descriptively reality as it is, i.e. without denying the existence of national political facts, while it also keeps the normative aspiration of building shared decision-making frameworks for the construction of democracy in Europe.

Keywords: dêmoicracy, political precariat, political equality, democratic inclusion

\section{Introducción}

Este artículo no pretende dar respuesta al conjunto de retos que en la actualidad condicionan el denominado proceso o proyecto de integración europea. Tampoco aspira a definir su potencial desarrollo a medio y corto plazo. Ese trabajo requeriría de un soporte técnico - en materia, sobre todo, de diseño institucional, políticas públicas, propuestas legislativas e incluso reforma de tratados - y empírico - en términos de evolución de comportamientos electorales, distribución de preferencias ciudadanas o esquemas de incentivos de partidos políticos - no sólo inabarcables en un único artículo sino, posiblemente, ajenos al ámbito específico de la filosofía política desde el que se plantea este análisis.

Por el contrario, este artículo propone dos cuestiones que se presentan como claves para entender la actual situación del proceso o proyecto de integración europea y su desarrollo futuro. Por un lado, la identificación del factor que en la última década parece condicionar en mayor medida el progreso del proyecto europeo: la pérdida gradual de estatus de una parte importante de la ciudadanía europea como resultado de la crisis. Por otro, las limitaciones que, de acuerdo con la evidencia de su implementación limitada, estéril o fallida ${ }^{1}$, presentan las visiones federal y soberanista tradicionales para revertir esa pérdida.

1 Joseph Lacey, Centripetal Democracy: Democratic Legitimacy and Political Identity in Belgium, Switzerland, and the European Union (Oxford: Oxford University Press, 2017); Daniel Innerarity et al., New Narrative for a New Europe (London: Rowman \& Littlefield International, 2018). 
La diferencia del contexto actual es que, frente a otros periodos de la breve pero intensa y fructífera historia del proyecto común europeo (reflejada, especialmente, en el desarrollo de la Unión Europea), la imposibilidad de alcanzar un amplio consenso que permita la implementación del modelo federal o soberanista clásico ya no parece soportable por una supuesta inercia de efectividad de los estados miembro. No en vano, la tesis cosmopolita de que los hechos políticos nacionales ${ }^{2}$ se presentan incapaces de dar respuesta a las necesidades políticas, económicas, culturales, medioambientales o sociales de la era de la globalización se ha visto definitivamente confirmada. Los retos que amenazan la democracia y sistema de bienestar en Europa (cambio climático, envejecimiento de la población o revolución digital) ya no pueden abordarse, de facto, en el ámbito exclusivo de los estados-nación. El equilibrio entre un proceso de integración imperfecto o por definir que se compensaba con la efectividad, por imperfecta que también fuera, de los estados miembro ya no es operativo.

Esto no significa que Europa esté abocada a repetir la barbarie a la que se vio sometida en diversas etapas del siglo XX. Los discursos catastrofistas que apelan a paralelismos con el periodo de entreguerras ignoran los mecanismos de control y contrapesos de los que dispone hoy en día la democracia en Europa, así como la fuerza normativa de democracias consolidadas. Sin embargo, huir de ese fatalismo con rasgos anacrónicos no puede implicar, si realmente se quiere corregir la deriva actual, negar la crisis de la democracia en Europa. Una crisis que, salvo contadas excepciones, no se manifiesta con estridencias traumáticas ni síntomas que alteren drásticamente la cotidianeidad (salvo en el caso de las personas más vulnerables). No obstante, presenta muestras de comprometer seriamente aquello que la democracia en Europa aspira a proteger

Siendo así, la necesidad de identificar debidamente el síntoma de esa degradación y plantear perspectivas que nos permitan pensar de forma efectiva cómo construir ese proyecto común resulta no ya teóricamente necesaria, sino empíricamente ineludible. Así como tras la Segunda Guerra Mundial el proyecto de integración europea fue capaz, fuera o no el propósito de sus promotores, de garantizar la paz y la convivencia en Europa, la construcción de un proyecto común se presenta hoy imprescindible para preservar la democracia en Europa. A continuación, el artículo esboza las bases de esta valoración sobre el escenario resultante de la crisis iniciada el 2008, antes de proceder con el análisis de sus efectos negativos más relevantes para el sistema democrático: la progresiva pérdida de igualdad política y

${ }^{2}$ Francis Cheneval y Kalypso Nicolaïdis «The social construction of demoicracy in the European Union», European Journal of Political Theory 16, 2 (2017) 235-260 
exclusión democrática de una parte sustancial de la ciudadanía europea. Es decir, la pérdida de estatus a la que se está viendo sometida el denominado «precariado político».

\section{Crisis de la democracia en Europa}

Lo primero que debemos valorar para poder hablar de la crisis de la democracia en Europa es su origen y dimensiones. Sin embargo, esta valoración requiere de un matiz previo fundamental que permita evitar la tentación de la mirada euroescéptica: la crisis que vivimos no es la crisis de la democracia europea o de la Unión Europea, sino la crisis de la democracia en Europa. La diferencia no es baladí: si bien el marco institucional europeo efectivamente ha presentado, a lo largo de las distintas etapas de su desarrollo, elementos negativos que han constituido un cierto «déficit democrático» ${ }^{3}$, no es menos cierto que esos déficits aplicaban en igual o mayor medida a los propios estados miembro. La fragmentación territorial de los intereses y preferencias de la ciudadanía, la pérdida paulatina de equilibrio entre la representación institucional y la soberanía popular, la dificultad de articular lazos de solidaridad horizontales y verticales en contextos cada vez más diversos y desiguales, o los riesgos de derivas populistas y tecnocráticas, por citar algunos ejemplos, no han sido carencias que las democracias nacionales hayan sabido esquivar.

Salvo excepciones puntuales ${ }^{4}$, la tendencia a poner el énfasis únicamente en la dimensión europea no se debe, por tanto, a un déficit democrático mayor en el ámbito europeo, sino a la persistencia metodológica de lo que Ulrich Beck vino a llamar mirada nacional ${ }^{5}$. Es decir, la formación de opiniones en contextos donde un nacionalismo más o menos banal ${ }^{6}$ lleva a interiorizar la existencia de los estados-nación como realidades naturales a partir de las cuales pensar la realidad política, en lugar de reconocer su ca-

${ }^{3}$ Richard Bellamy, «The inevitability of a democratic deficit», en Key Controversies in European Integration, ed. por Hubert Zimmermann y Andreas Dür (New York: Palgrave, 2012) 64-71.

${ }^{4}$ Iñigo Bullain, «El proceso de oligarquización europeo. De la utopía federal a una distopía social y democrática». Cuadernos Europeos de Deusto 54 (2016): 59-98; Iñigo Bullain, «Europaren Distopia Globalizazio Oligarkikoan». Europa Krisiz Krisi: korapiloa askatzen / Europa en crisis: análisis y propuestas (EuroBasque, 2018), Jule Goikoetxea, Privatizing Democracy: Global Ideals, European Politics and Basque Territories (Bern, Switzerland: Peter Lang UK, 2017).

5 Ulrich Beck, Cosmopolitan Vision (Cambridge: Polity Press, 2006).

${ }^{6}$ Michael Billig, Banal Nationalism (London: SAGE Publications, 1995); Jorge Cagiao y Conde, Micronacionalismos: ¿No seremos todos nacionalistas? (Madrid: Catarata, 2018). 
rácter de ficciones contingentes ${ }^{7}$. Operativas, potencialmente ${ }^{8}$, pero ficciones en todo caso. $\mathrm{Si}$, en cambio, se asume una posición metodológica que permita no presuponer las bondades del estado-nación ni fijarlo como punto de partida del análisis, asumiendo su contingencia y falibilidad históricas, se observa que la crisis de la democracia en Europa afecta, cuanto menos, en igual medida al ámbito estatal como al de la unión. Una posición metodológica que Beck denominó «mirada cosmopolita» y que permite evaluar de manera más ajustada la realidad cosmopolitizada de la Europa del siglo XXI.

Una vez aclarada esta cuestión metodológica, podemos retomar la descripción de la crisis de la democracia en Europa. Una crisis que, además, no afecta únicamente al ámbito europeo. Tal y como detallan Fernando Vallespín y Mariam M. Bascuñán ${ }^{9}$, la actual crisis de la democracia se refleja a nivel global en base a diversos factores, destacando el carácter reactivo de la política en las postrimerías del final de la Guerra Fría, la crisis del elemento representativo y de los partidos políticos (o, como afirma Daniel Innerarity, la crisis de la intermediación $\left.{ }^{10}\right)$ y, como aspecto fundamental, el carácter más bien discursivo de la nueva política en contraposición a las grandes ideologías del Siglo Xx capaces de ordenar las sociedades entorno a bloques más o menos manejables políticamente.

Durante la segunda mitad del siglo xx la idea de que la democracia liberal había conquistado un nivel de estabilidad y arraigo irreversibles fue adquiriendo más peso ${ }^{11}$, especialmente con relación a contextos geográficos denominados occidentales. Sin embargo, el propio fenómeno de la globalización nos ha permitido observar que ni la democracia liberal es irreversible ni es un fenómeno propiamente occidental ${ }^{12}$. Frente a aquella creencia de que el sistema democrático liberal constituía un sistema institucional y regulativo infalible a la hora de canalizar la conflictividad de una sociedad plural, nuevos fenómenos políticos ${ }^{13}$ nos permiten observar que la dis-

7 Benedict Anderson, Imagined Communities: Reflections On the Origin and Spread of Nationalism (London; New York: Verso, 2006).

${ }^{8}$ Craig Calhoun, Nations Matter: Culture, History and the Cosmopolitan Dream (Oxon ; New York: Routledge, 2007)

${ }_{9}$ Fernando Vallespín y Máriam M. Bascuñán, Populismos (Madrid: Alianza Editorial, 2017).

10 Daniel Innerarity, La Política en Tiempos de Indignación (Barcelona: Galaxia Gutenberg: 2015).

${ }^{11}$ Francis Fukuyama, The End of History and the Last Man (New York: Free Press, 1992).

12 Richard Young, The Puzzle of Non-Western Democracy, (Washington: Carnegie Endowment for International Peace, 2015). 2018)

${ }^{13}$ Steven Levitsky y Daniel Ziblatt, Cómo mueren las democracias (Barcelona: Ariel, 
crepancia vuelve a plantearse a nivel global desde una lógica de puro conflicto, sin concesiones ${ }^{14}$, llevando la polarización política a tales extremos que lleva a cuestionarse si el propio sistema institucional será capaz de soportarlo. Esto lleva a pensar que, en el mejor de los casos, esa cualidad que se atribuía a los sistema democrático-liberales era el resultado de la buena voluntad o incentivos coyunturales de los actores que en ella operaban, no el resultado automático de su implementación jurídica o institucional. Es decir, la hipótesis de que el propio sistema democrático-liberal generaba incentivos para la gestión cooperativa de la discrepancia se ha probado errónea: se han de generar las condiciones, subjetivas u objetivas, para que la cooperación sea el elemento que defina las dinámicas sociales. Un ejercicio que requiere, a fin de orientar la generación de esas condiciones, de una reflexión sobre la base normativa de la democracia, es decir, del deber ser.

En términos normativos, como afirma Teresa M. Bejan ${ }^{15}$, nos encontramos en una coyuntura en la que, a escala global, el ejercicio de la política se ha distanciado efectivamente de uno de los principios fundacionales que permitieron la operatividad de la democracia liberal desde sus orígenes: la civilidad (mere-civility). De acuerdo con este principio, la teoría democrática no niega que la discrepancia, incluso sustancial o fundamental, sea intrínseca a toda sociedad plural (lo que en el siglo XXI equivale a decir «toda sociedad»). La civilidad - al contrario de lo que algunos usos del lenguaje ordinario consideran - no consiste en la negación u omisión de esa discrepancia. La civilidad consiste, precisamente, en aceptar que podemos discrepar sin negar o destruir la posibilidad de construir un proyecto común con aquellos y aquellas con los que discrepamos. Frente a una deriva de la política en la que se plantea la dicotomía entre reducir e incluso suprimir la discrepancia o plantearla en términos de suma cero (i.e., ha de prevalecer mi posición o la de aquél de quien discrepo), la civilidad implica expresar la discrepancia a la par que se reconoce la existencia legítima del otro discrepante. La negación de este principio fundamental en el ejercicio de la política, también expresable en términos de deterioro de la tolerancia mutua ${ }^{16}$, está sometiendo los sistemas democráticos globales a unos niveles de estrés inusitados en la segunda mitad del siglo Xx. La civilidad, en definitiva, no

${ }^{14}$ Levitsky et al, Cómo mueren... 173-183.

15 Theresa Bejan, «The bond of Civility: Roger Williams on toleration and its limits», History of European Ideas 37 (2011), Theresa Bejan, T. «Difference without Disagreement: Rethinking Hobbes on "Independency" and "Toleration"», The Review of Politics 78 (2016) 2, Theresa Bejan «The Bond of Civility: Roger Williams on toleration and its limits», History of European Ideas 37, 4 (2011) 417, Theresa Bejan, «Evangelical Toleration», The Journal of Politics 77,4 (2015) 6

${ }^{16}$ Levitsky et al, Cómo mueren... 17 
aspira a construir un marco jurídico-institucional perfecto. Por el contrario, asume la imperfección tanto de los sujetos que operan en una democracia como del equilibrio resultante de su interacción democrática, permitiendo a su vez su cauce ordenado.

Esta crisis de la democracia tiene una expresión específica en el entramado institucional europeo, correspondiente a su elevado nivel de interacciones complejas. No en vano, la primera crisis que afecta a la democracia en Europa es, precisamente, una crisis de inteligibilidad ${ }^{17}$ : la ciudadanía, así como sus representantes institucionales, presentan serias dificultades para conocer (no, necesariamente, por falta de transparencia ${ }^{18}$ ) tanto los fenómenos que condicionan sus vidas como los mecanismos de los que disponen para regularlos. Así, los síntomas de la crisis global de la democracia adquieren una forma específica en Europa.

Parece un elemento de consenso afirmar que la crisis de la democracia tuvo su detonante en la crisis económica del 2008 que, en el caso europeo, derivaría en la crisis del euro ${ }^{19}$. Sin embargo, a diferencia de otras latitudes, en el caso de Europa esta crisis adquirió dimensiones sistémicas que trascendían la dimensión meramente económica o política. Es decir, en el caso europeo la crisis fue y está siendo más bien multidimensional ${ }^{20}$ : financiera, fiscal, presupuestaria, administrativa, de gobernanza, constitucional, social, cultural e, incluso, de valores. Dicho en otras palabras: suceda lo que suceda en Brasil o Estados Unidos, por citar dos casos donde la democracia también está en crisis, nada hace pensar que la existencia de Brasil o Estados Unidos como hechos políticos (nacionales, en su caso) esté en riesgo en el corto-medio plazo. En el caso de Europa, la crisis multidimensional de la democracia puede afectar su actual existencia. Es decir, tiene compo-

17 Daniel Innerarity, La Democracia en Europa (Barcelona: Galaxia Gutenberg, 2017)

18 En este punto resulta fundamental, en una época marcada por la incidencia de los flujos crecientes la distinción entre datos, información y conocimiento. No en vano, la mayor cantidad de datos e información no genera, en sí misma, un mayor conocimiento. Es decir, si entendemos por transparencia un mayor acceso a datos e información, se podría afirmar que la transparencia es una condición necesaria para la democracia, pero no una condición suficiente. No en vano, la mejora de la calidad democrática resulta de un mayor conocimiento, es decir, de una mejor interpretación de datos y una mejor lectura de la información. Para explorar más a fondo esta idea: Daniel Innerarity, La Democracia del Conocimiento (Barcelona: Paidós, 2011).

${ }^{19}$ Claudia Sternberg, Kalypso Nicolaïdis y Kira Gartzou-Katsouyanni, The Greco-German Affair in the Euro Crisis: Mutual Recognition Lost? (London: Palgrave, 2018)

20 Joxerramon Bengoetxea, «The current European Crises: the end of pluralism?», en The future of Europe: democracy, legitimacy and justice after the euro crisis, ed. por Serge Champeau, Carlos Closa, Daniel Innerarity y Miguel P. Maduro (London: Rowman \& Littlefield International, 2104) 
nentes de crisis existencial. Esto no implica que el espacio europeo ${ }^{21}$ vaya a desaparecer: sino que su aspiración de proyecto común de democracia está siendo profundamente cuestionada ${ }^{22}$.

Ello se debe, en buena medida, a que en la Europa de las interdependencias $^{23}$ las diversas dimensiones de la crisis se alimentan entre sí. Prueba de ello son las dificultades de las instituciones europeas para atajar la sucesión de crisis a las que se ha enfrentado la democracia en Europa desde el 2008: la incapacidad de dar una respuesta común a la denominada «crisis de los refugiados» y la inhumana situación tolerada en el mediterráneo o los Balcanes, el proceso (aún incierto) de salida del Reino Unido de la Unión Europea, el auge de los populismos nacionalistas y movimientos de extrema derecha, la incapacidad de fijar una posición común en política exterior (lo que genera debilidad ante amenazas, como en el caso de Rusia, o pérdida de posición como actor global) o la dificultad de promover la protección de derechos fundamentales frente a quienes se justifican en la soberanía nacional para amparar su vulneración (siendo los casos de Hungría o Polonia los más acuciantes, si bien ciertos excesos cometidos por España en relación al caso catalán podrían situarse en este mismo terreno ${ }^{24}$ ).

En este escenario de crisis de la democracia a escala global y crisis multidimensional en Europa podemos identificar un elemento transversal que, en el caso de Europa, resulta ineludible para entender la reacción de la ciudada-

${ }^{21}$ Kalypso Nicolaïdis y Juri Viehoff «Just boundaries for demoicrats», Journal of European Integration 39:5 (2017) 591-607

${ }^{22}$ Se podría plantear si, en el fondo, el proyecto de integración europea no se limita a la creación de un espacio de libre mercado. En ese sentido, la pulsión entre quienes aspiran a avanzar en la creación de una comunidad política y quienes conciben su aspiración desde la perspectiva del mercado único ha sido una constante del debate político en torno al proyecto europeo. Sin embargo, este debate se ha referido más bien a propuestas de diseño institucional contrapuestas, siendo así que los partidarios de una u otra opción (así como de los múltiples matices intermedios) coincidían en la aspiración paralela de que el espacio europeo fuera un espacio democrático. Como explicaré en la sección tres, la propuesta dêmoicratica pretende, precisamente, cambiar el enfoque desde le que se plantea el debate sobre el proyecto europeo para que adopte una visión más pragmática en la que esta aspiración de proyecto común de democracia y libre mercado sea la premisa y no el resultado a alcanzar mediante la aplicación de uno u otro diseño institucional en la escala supranacional.

23 Thomas Hale and David Held, Beyond the Gridlock (New York: Polity Press, 2017).

${ }^{24}$ El informe de Aministia Internacional del 17 de noviembre del 2017 o la declaración del 15 de octubre del 2018 solicitando la libertad de Jordi Cuixart (presidente de Omnium Cultural) y Jordi Sánchez (expresidente de la Assamblea Nacional Catalana y actualmente parlamentario por Junts per Catalunya), así como la declaración de Human Rights Watch del 12 de octubre del 2012 serían dos de los múltiples ejemplos de denuncias internacionales en ese sentido. 
nía: el incremento de las desigualdades económicas ${ }^{25}$. Sin pretensión de desarrollar la valoración empírica con carácter exhaustivo, resulta imprescindible introducir este factor en tanto que la tercera sección abordará su impacto en la democracia desde la perspectiva de la filosofía política. No en vano, en esa vorágine de deterioro de la democracia y crisis multidimensional, el incremento de las desigualdades económicas en Europa permite entender la reacción de buena parte de la ciudadanía en cada uno de los casos sintomáticos de esa crisis. Fenómenos como el Brexit y su apelación a la soberanía nacional excluyente, las pulsiones proteccionistas en Italia, el auge de un populismo nacionalista y de extrema derecha como reacción a las políticas de acogida de personas refugiadas, o la propia tensión entre el reclamo democrático en favor de la autodeterminación de Catalunya y la consiguiente reacción basada una visión monolítica de la constitución española, entre muchas expresiones de la crisis multidimensional que vivimos en Europa, difícilmente se pueden explicar sin atender al incremento de las desigualdades económicas.

Esto no implica considerar las desigualdades como único factor explicativo. Tampoco que los citados fenómenos y su expresión local ad-hoc puedan capturarse atendiendo a un único factor (prueba de ello sería la divergencia con la que, por ejemplo, se ha expresado el fenómeno del Brexit a lo largo del propio Reino Unido ${ }^{26}$ ). En un contexto de complejidad creciente, pretender explicar fenómenos sociopolíticos con un único elemento causal o de manera lineal resulta cada vez más desviado analíticamente. No obstante, ello no es óbice para reconocer la existencia de factores con una mayor incidencia sobre estos fenómenos, especialmente cuando se presentan de forma transversal como en el caso de las desigualdades. Tal y como explica José Fernández-Albertos, «el crecimiento en los apoyos a opciones antisistema sucede en buena medida como respuesta a la gran recesión, tiende a concentrarse en zonas geográficas en declive y se nutre de votantes que se sienten hoy económicamente más vulnerables que en el pasado» ${ }^{27}$. Es decir, la precariedad económica de una parte importante de la ciudadanía les hace más vulnerables y, en consecuencia, modifica la manera en que las emociones en general y el miedo en particular ${ }^{28}$ condicionan su forma de participar en la política entendida como implicación en lo común.

25 Thomas Piketty, Capital in the Twenty-First Century, (Cambridge: Harvard University Press, 2014), Branko Milanovic, Global Inequality: A New Approach for the Age of Globalization (Cambridge: Harvard University Press, 2016)

${ }^{26}$ Michael Keating, «Brexit and the Territorial Constitution of the United Kingdom», Droit et société 98, 1 (2018) 53-69

27 José Fernández-Albertos, Antisistema: Desigualdad Económica y Precariado Político (Madrid: Catarata, 2018) 53

${ }_{28}$ Dídac Gutiérrez-Peris, «Nuevo realineamiento del miedo en Francia y en Europa», Cuadernos Europeos de Deusto 59, editado por Cristina Astier y Ander Errasti (2018) 99-114 
Sin embargo, la creciente incidencia de las emociones negativas en política no ha de suponer un rechazo de la dimensión emocional o subjetiva de la política. Es decir, si bien las desigualdades económicas (combinadas con la proliferación de entornos digitales que aceleran e incrementan exponencialmente la interacción entre la ciudadanía) han auspiciado el incremento del miedo como factor determinante de la política (en términos de comportamientos electorales o valores de la ciudadanía), la solución no pasa por eliminar la dimensión subjetiva. La visión tecnocrática de la política acostumbra a concebir la ciudadanía como un sujeto pasivo cuya participación en la política ha de responder a los elementos de racionalidad que presuponen los procedimientos formales previstos en democracia. Así, se parte de la idea de que el ciudadano influye sobre las instituciones representativas optando entre opciones que permiten controlar, si no eliminar, el peso de la emocionalidad en la toma de decisiones. Sin embargo, la historia de la democracia y, sobre todo, su progreso nos muestra que no se ha obviado la dimensión subjetivo-emocional, sino que ha sido un motor de transformación fundamental.

Recuperar el principio de civilidad de la democracia no pasa, por tanto, por revertir o tutelar la dimensión emocional, sino por corregir las condiciones materiales que llevan a que se generen y acentúen determinadas emociones que dificultan su práctica. Especialmente cuando esas emociones son canalizadas por posicionamientos políticos que ponen en riesgo la pervivencia del propio sistema democrático. Porque, en definitiva, como el propio Fernández-Albertos afirma ${ }^{29}$, no es el incremento de la desigualdad económica el factor decisivo para explicar la crisis de la democracia, sino su capacidad de exclusión. Lo que permite entender la incidencia del auge de las desigualdades en los sistemas democráticos es el surgimiento de un precariado político como consecuencia de esas desigualdades. Un precariado político que, en definitiva, percibe que el sistema político ya no tiene incentivos ni mecanismos para incluir sus intereses en la ponderación de la pluralidad de intereses que ha de articular un sistema democrático. Sea por la ineficacia de los sistemas redistributivos en una economía globalizada (lo que se ha venido a llamar perdedores de la globalización), por la incerteza (más o menos justificada ${ }^{30}$ ) ante el impacto de la revolución tecnológica o, incluso, por las consecuencias desiguales del proceso de desindustrialización o terciarización, las sociedades democráticas ven como la nueva estructura social desplaza ciertos sectores de la población a un espacio políticamente irrelevante. Un espacio en el cual los incentivos para optar por opciones que busquen revertir el sistema sean más sólidos.

29 José Fernández-Albertos, Anti-sistema... 80

30 José Fernández-Albertos, Anti-sistema... 65 
Frente a este fenómeno, la alternativa no es el rechazo a la dimensión subjetiva de la reacción de ese precariado político, entre otras razones porque se ha probado que resulta contraproducente ${ }^{31}$. Tampoco una reacción paternalista, próxima al despotismo ilustrado, que pretenda dar respuesta a las causas de ese malestar sin contar con la parte de la ciudadanía que expresa ese malestar. La respuesta, sugiere este artículo, pasa por volver a situar en el centro de los sistemas democráticos (y, por ende, del diseño de agendas políticas, instituciones, legislación o políticas públicas) los principios fundamentales de la democracia: la igualdad política y la inclusión democrática. Unos principios que, en definitiva, garanticen el valor fundamental de todo sistema democrático: la igualdad de estatus de la ciudadanía. No en vano, así como el marco jurídico-institucional no genera la ausencia de conflicto, un sistema que garantice la igualdad de estatus será más propenso a fomentar la civilidad necesaria para aproximarnos al orden al que aspiran las democracias-liberales. Qué mejor espacio que el europeo, con la Unión Europea como su expresión política central y con todo su potencial de transformación transnacional, para pensar cómo recuperar estos principios, revirtiendo la actual crisis en una oportunidad democrática. Antes de avanzar un enfoque que podría facilitar ese giro veamos, primero, en qué consisten estos principios de igualdad política e inclusión democrática.

\section{La importancia de la inclusión democrática y la igualdad política}

La democracia puede definirse como el conjunto de procesos y normas que las sociedades desarrollan para canalizar su diversidad y divergencia internas a fin de facilitar la solidaridad, la cooperación y la convivencia entre ciudadanos y ciudadanas autónomas. Es decir, se trata de una forma de toma de decisión o autogobierno colectiva. Esta sería una concepción básica de la democracia que cubre tanto su dimensión de legitimidad de origen como de resultado. A lo largo de la historia y en la actualidad, una diversidad de estudiosos de la democracia ha reflexionado y debatido sobre la mejor manera de materializar ambas dimensiones. Sin embargo, previo a estos debates, la democracia se sostiene sobre un principio sin el cual resulta inoperante: la igualdad política. Es decir, independientemente de otros principios relevantes que podamos plantear como base para un sistema democrático (la no-dominación, por ejemplo, en un modelo republicano), así como del valor instrumental que le queramos otorgar (como su capacidad de pro-

${ }^{31}$ La victoria de Donald Trump sobre Hillary Clinton estuvo condicionada, entre otros factores, por el desprecio que ese mismo precariado político había percibido por parte de quienes defendían las posiciones próximas a Clinton. 
mover la justicia distributiva, por ejemplo), es común reconocer la igualdad política como característica fundamental de todo sistema democrático.

¿De qué hablamos cuando hablamos de igualdad política? Como en cualquier concepto no relativo, pero sí esencialmente controvertido ${ }^{32}$ (es decir, su significado resulta de la deliberación, no le precede), el significado concreto de la igualdad política varía en función de la teoría de la democracia que consensuemos. Lo mismo aplicaría, por ejemplo, al concepto de libertad democrática: su significado concreto podrá variar en función de la posición que consensuemos (autonomía, si se aceptan las tesis liberales, nodominación, en el caso del republicanismo, por ejemplo). Sin embargo, esto no implica que el valor de la libertad en una democracia sea relativo: es necesario trabajar un consenso mínimo para determinar en qué consiste. Lo mismo ocurre con la noción de igualdad política, que vendría a referirse a la igualdad de valor de los individuos de un colectivo implicado en la toma de decisión en el sentido de que existan mecanismos (formales o informales) que les garanticen un poder de decisión equitativo. No se refiere (aunque de él pueda derivarse), a la igualdad entre seres humanos que pudiera sostenerse en teoría moral ${ }^{33}$, sino a la igualdad consustancial al hecho de la ciudadanía democrática.

Como es habitual en teoría política, resulta más esclarecedor concretar un concepto esencialmente controvertido apelando a una explicación negativa, es decir, citando casos que, sea cual sea la concepción que se asuma del principio, no quepa duda de que lo vulneran. En el caso del principio de igualdad política, la estructura de Apartheid que durante décadas operó en Sudáfrica, el sistema de organización social en castas o el régimen saudí que relega a la mujer a una posición secundaria serían ejemplos de esquemas políticos donde no se respeta el principio de igualdad política. Incluso en los ejemplos históricos de democracia a los que en teoría política se apela con frecuencia, la antigua Grecia o la constitución estadounidense del Siglo XVIII, la igualdad política brillaba por su ausencia en tanto en cuanto las personas esclavas no tenían reconocida la capacidad de participar en el proceso de toma de decisión. En definitiva, si bien el debate sobre la concreción del principio continúa abierto con relación al presente y futuro de la democracia, resulta plausible consensuar su contenido respecto a sistemas políticos pasados. Dicho lo cual, a efectos de operatividad del argumento podríamos afirmar, siguiendo a John Locke ${ }^{34}$, que la igualdad política su-

32 Marisa Iglesias, «Las causas de indeterminación del Derecho: una aproximación filosófica», Cuadernos de derecho público 28 (2006) 5582

33 Simon Caney, Justice Beyond the Borders (Oxford: Oxford University Press, 2005)

${ }^{34}$ John Locke, Two Treaties of Government, ed. por Peter Laslett (Cambridge: Cambridge University Press, 1988). 
pone garantizar que todos los seres humanos tienen el mismo derecho para autorizar las leyes que rigen sus vidas. Un principio que, como afirmaba Isaiah Berlin ${ }^{35}$, una vez la sociedad se constituye como democrática, no es necesario justificar.

¿Significa esto, no obstante, que la democracia no acepte desigualdades o asimetrías? Más bien al contrario: como sostienen la mayoría de las teorías democráticas contemporáneas, los sistemas democráticos exigen en muchos casos un trato desigual para garantizar la igualdad política. Ejemplo de esta derivada del principio serían, por ejemplo, las medidas de acción afirmativa y cuotas para garantizar la igualdad de género, los mecanismos de sobrerrepresentación de minorías etnolingüísticas, grupos indígenas o LGBTI+ o los equilibrios de reparto de poder político en modelos de distribución territorial federal, compuesto o plural. En todos ellos, la igualdad política no se aplica en sentido estricto, dado que no toda la ciudadanía tiene idéntica capacidad de influir sobre el proceso de toma decisiones que les afecta. Sin embargo, se parte de la premisa de que la igualdad política - y los principios democráticos en general - no se aplica en contextos o estructuras homogéneas, sino diversas, desiguales, parciales. La justicia entendida como equidad exige, por tanto, aplicar mecanismos que garanticen no sólo la igualdad política formal sino también efectiva. Un planteamiento que, en todo caso, no vulnera la máxima de Berlin, precisamente porque todas estas desviaciones del principio de igualdad política se aplican en la medida en que existe una justificación sólida para ello. Es decir, no es la igualdad política la que se ha de justificar, sino la desviación.

Ahora bien, a efectos del artículo, ¿por qué es tan relevante la igualdad política? Tal y como afirma Sofia Näsström, la igualdad política es fundamental en un sistema democrático por su «fuerza normativa» ${ }^{36}$. Es decir, precisamente por el hecho de que una vez aceptamos que vivimos en un sistema democrático, la igualdad política no requiere de justificación. Es más, si requerimos de una justificación para aquellas desviaciones que consideramos legítimas es, justamente, porque estas desviaciones han de servir al propósito de reforzar la igualdad política. El principio de igualdad política, en ese sentido, subyace a todo intento de avanzar en la calidad de un sistema democrático: cuanto más reflexionemos críticamente sobre cómo justificar desviaciones del principio de igualdad política a fin de garantizar efectivamente la igualdad política de la ciudada-

35 Isaiah Berlin, Concepts and Categories, ed. por Henry Hardy (Princeton: Princeton University Press, 1999) 84

36 Sofia Näsström, «Normative Power of Political Equality», en Political Equality in Transnational Democracy, ed. por Eva Erman y Sofia Näsström (New York: Palgrave McMillan, 2013). 
nía, más sólido será el sistema democrático. Por el contrario, cuanto más defendamos el estatus-quo formal como estadio último de la igualdad política en una democracia, más probabilidades habrá de que ese sistema democrático perpetúe, de facto, la vulneración de la igualdad política de una parte de la ciudadanía. En esta sencilla pero potente idea de «fuerza normativa» del principio de igualdad política reside, en definitiva, el potencial de progreso democrático.

Un progreso democrático que, sin embargo, en el contexto de la globalización en general y de la integración europea en particular, se enfrenta a otro reto estrechamente vinculado al principio de igualdad política: su aplicación más allá de las fronteras del estado-nación. Es decir, la ampliación del otro gran principio en un sistema democrático: la inclusión democrática. Una vez aceptamos el principio de que, en democracia, todos los individuos han de poder participar sobre las decisiones que afecten a sus vidas, debemos definir quienes constituyen ese conjunto de individuos que deciden democráticamente. Es decir, la teoría democrática ha venido asumiendo (posiblemente por el mismo nacionalismo metodológico al que se ha apelado antes) que el principio de igualdad política aplicaba a todos los individuos que compartían la misma nacionalidad o ciudadanía. Sin embargo, en el contexto de la globalización en general y la integración europea en particular, esta premisa no resulta válida normativa ni políticamente. No en vano, frente al carácter esencialmente controvertido del principio de igualdad política, la inclusión democrática se caracteriza por un elemento que dificulta su análisis: su expresión concreta está condicionada por el contexto y circunstancias históricas en las cuales se plantea ${ }^{37}$. Así, en un contexto de primacía de los estados-nación como unidades políticas autocontenidas, se asumía que la máxima de que la igualdad política aplica a los sujetos que se ven afectados por un proceso de toma decisión debía aplicarse entre connacionales. En un contexto de interdependencias como el actual, ¿continúa siendo válido asumir esta aplicación restrictiva del principio?

Desde un punto de vista descriptivo, es cuestionable que ni siquiera en el contexto de primacía de los estados-nación aplicar automáticamente esta máxima fuese estrictamente válido. Como sostiene Näsström, la instauración de los sistemas democráticos modernos implicó que grupos que en la mayoría de los casos no compartían un mismo origen (fuese económico, social, político o religioso) defendieran la igualdad política. Es más, en contextos de estados nacionalmente fragmentados (como Es-

37 Rainer Bauböck «Democratic inclusion: a pluralist theory of citizenship», en Democratic Inclusion in Dialogue, ed. por David Owen (Manchester: Manchester University Press, 2018) 5 
paña, Reino Unido, Canadá o Bélgica, por citar cuatro ejemplos ampliamente reconocidos ${ }^{38}$ ) también se interiorizó entre la ciudadanía la defensa del principio de igualdad política sin tan siquiera compartir, necesariamente, un mismo vínculo nacional. Lo mismo sucede si observamos la compatibilidad entre el incremento de movimientos migratorios y la persistencia del principio de igualdad política. En ese sentido, no parece que la defensa de un sistema democrático sustentado, necesariamente, en el principio de igualdad política sea el resultado de un patriotismo nacional o constitucional que vincula a la ciudadanía a un elemento común, sino a otro patrón más vinculado a la propensión a vivir en contextos democráticos donde sus intereses puedan ser tenidos en consideración. Esto no significa que no existan patrones de vinculación comunitaria dentro de un sistema democrático, sino que el sistema democrático no se sostiene sobre esos patrones comunitarios. Si aceptamos esta premisa - ciertamente aún sin resolver - sobre el origen de las democracias modernas, desde un punto de vista político no debería ser problemático afirmar que en un contexto transnacional como el europeo la inclusión democrática podría ser perfectamente compatible con el principio de igualdad política.

Desde un punto de vista normativo las razones para ello son más sólidas si cabe: como afirma Innerarity, la autodeterminación en un contexto de interdependencias como el europeo sólo puede justificarse en la medida en que sea transnacional ${ }^{39}$. No en vano, las decisiones que afectan a los individuos ya no se restringen a las adoptadas en los órganos de decisión nacionales. Asimismo, las decisiones que un conjunto de individuos adopta en los órganos de decisión nacionales afectan a individuos situados fuera de ese marco de decisión nacional. La reflexión sobre el principio de inclusión democrática trata, precisamente, de adaptar la teoría de la democracia a estas nuevas realidades. Asumir que el único marco válido para la reflexión sobre la democracia es una división de fronteras políticas que resulta no sólo arbitrario desde un punto de vista moral ${ }^{40}$, sino en muchos casos fruto de procesos injustos ${ }^{41}$, es negar su carácter contingente. Esto no implica negar el hecho en sí de la frontera, con su consecuente lógica de inclusión/ exclusión, sino negar que esas fronteras sean puntos de partida absolutos

38 Michael Keating, Plurinational Democracy on a Post-Sovereignty Era, (Oxford: Oxford University Press, 2002), Alain Gagnon, The Case for Multinational Federalism: Beyond the allencompassing nation, (London. Routledge, 2009)

39 Daniel Innerarity, «Transnational Self-determination. Resetting Self-Government in the Age of Interdependence», JCMS: Journal of Common Market Studies, 53 (2015) 10611076

40 Simon Caney, Justice...

${ }^{41}$ Kalypso Nicolaïdis, Berny Sèbe y Gabrielle Maas, eds., Echoes of Empire: Memory, Identity and Colonial Legacies (London: I. B. Tauris, 2015) 
de la reflexión sobre la democracia. La clave, por tanto, no está en relegar las fronteras al terreno de lo natural ni considerarlas un elemento abstracto del que se pueda prescindir en la reflexión normativa: la clave está en asumir que, si bien su existencia es propia de un sistema democrático, su impacto sobre el funcionamiento de la democracia es variable. Como afirma Rainer Bauböck, «la democracia no sería necesaria en ausencia de una diversidad de intereses, identidades e ideas, y no sería posible en ausencia de fronteras» ${ }^{42}$.

En la medida en que aceptamos que la democracia legitima cierto grado de delimitación formal de la pertenencia y marco territorial, la necesidad de reflexionar sobre quién puede participar o no en la toma de decisión se sigue lógicamente. De hecho, ha sido una constante en relación, sobre todo, a personas migrantes o migradas. Sin embargo, en un contexto de globalización, la lógica de la reflexión se vertebra no tanto en base a la pertenencia o lógica de inclusión/exclusión, como al intento de adaptar la noción de «afectados» a las nuevas realidades cosmopolitizadas donde la categoría se vuelve más liquida. Esta circunstancia, auspiciada en buena medida por el incremento de las interdependencias fácticas generadas por la globalización ${ }^{43}$, adquiere una dimensión institucional en el espacio europeo. Así como en el ámbito global la aplicación del principio de inclusión democrática, en sus variantes teóricas ${ }^{44}$ de ciudadanía implicada (all citizenship stakeholders), intereses afectados (all affected interests) o agentes sujetos a las decisiones (all subjected to coercion) resulta más difícil de concretar, en el ámbito europeo la implicación, los intereses afectados o los sujetos coercidos son más trazables empíricamente. En consecuencia, no pueden ser ignorados en la reflexión normativa.

Es decir, si aceptamos que el principio de inclusión democrática se refiere, en última instancia, a la legitimidad de la toma de decisiones sobre un marco delimitado (habitualmente territorial, pero no necesariamente), la inclusión democrática se refiere a la relación entre un individuo o grupo que aspira a formar parte de de ese marco de decisión y un colectivo de individuos que aspiran a ser regidos por un marco delimitado de decisión legítimo. La inclusión, por tanto, se basa en responder satisfactoriamente a lo primero para garantizar con éxito lo segundo: somos inclusivos para vivir en un régimen democrático legítimo. Si aceptamos que lo que determina la condición de principio fundamental de la

42 Rainer Bäubock, «Democratic...», 7

43 Ulrich Beck, ¿Qué es la globalización? Falacias del globalismo, respuestas a la globalización (Barcelona: Paidós, 1997), Martin Albrow, The Global Age (Cambridge: Blackwell Publishers Polity Press, 1996)

${ }^{44}$ Rainer Bäubock, «Democratic...», 22-47 
igualdad política para legitimar un sistema democrático es que todo individuo ha de poder participar por igual en las decisiones que afectarán a su vida, y sabemos que en el espacio europeo esas decisiones ya no están restringidas al ámbito de los hechos políticos nacionales, de ello se sigue que un sistema democrático nacional legítimo en Europa ha de ser necesariamente inclusivo.

Siendo así, ¿qué ocurre cuando sucede un fenómeno como el incremento del precariado político como resultado del aumento de las desigualdades? Por un lado, se vulnera el principio de igualdad política. Por otro, se yerra a la hora de articular la inclusión democrática. Se vulnera el principio de igualdad política en tanto que el sistema se articula de tal manera que los intereses de una parte de la ciudadanía (el precariado político) no son contemplados por los representantes políticos encargados de su ponderación en la toma de decisiones. Si bien formalmente parecen estar incluidos, de facto quedan excluidos. Esto no implica que las alternativas que se valen de la crisis de la democracia sean la solución: tampoco ellas tienen por objetivo, a efectos de este artículo, introducir los cambios necesarios para garantizar la igualdad política de facto (más bien al contrario). Sin embargo, la tendencia del precariado político a optar por opciones anti-sistema no justifica que se ignore a estos votantes. Es decir, no justifica la vulneración de facto del principio de igualdad política al que se está sometiendo a esa parte, cada vez mayor, de la ciudadanía.

En cuanto al principio de inclusión democrática, se sigue tratando de abordar el surgimiento de este precariado político (con la desigualdad como factor causal determinante) y su impacto en la política desde una óptica estrictamente nacional. Así, la crisis multidimensional de la democracia en Europa se sigue planteando como crisis autárquicas de la democracia en Austria, Italia, Holanda, Alemania, Reino Unido o España. De este modo, se obvia que las decisiones que han causado la crisis multidimensional eran eminentemente transnacionales. Es decir, en la competición nacional por superar la crisis de la democracia, se continúa tomando decisiones políticas en las que únicamente se tiene en cuenta el electorado nacional. De este modo, se obvia que la causa principal de la crisis de la democracia en Europa, la que permea su carácter multidimensional, es un precariado político que no sólo es común a toda Europa, sino que es también causada por una gestión deficiente de las interdependencias europeas. No tenerlas en consideración en el ámbito nacional vulnera el principio de igualdad política. No tener en cuenta su carácter transnacional vulnera el principio de inclusión democrática. Sin embargo, ¿existe alguna alternativa? Es ahí donde la propuesta dêmoicratica permite abrir un espacio para la reflexión innovadora. 


\section{La transformación dêmoicratica}

La propuesta dêmoicratica se basa en el prisma del reconocimiento. Es decir, en la idea del reconocimiento del otro en su otredad auto reconocida (es decir, no impuesta por quien reconoce, tanto epistémicamente como en su identidad y valores ${ }^{45}$ ) así como el compromiso de garantizar a ese otro el debido respeto y dignidad humana como premisas necesarias para transformar relaciones que, por definición en un contexto diverso, son desiguales. Un reconocimiento que, además, exige reciprocidad, es decir es un reconocimiento mutuo. Una reciprocidad que, cuando se trata de colectividades, tiene efectos normativos tanto hacia el interior como hacia el exterior. Es decir, es un prisma que permite promover una determinada posición normativa respecto a aquellos que pertenezcan a la colectividad y respecto a aquellos que quedan fuera. En definitiva, la consideración del reconocimiento mutuo como perspectiva normativa implica rechazar toda propuesta que busque la homogeneidad ad-intra y la dominación ad-extra, puesto que serían incompatibles con la definición del reconocimiento-mutuo. No en vano, el reconocimiento mutuo parte de que la aspiración que un sujeto pueda tener por ser reconocido ha de partir de su disposición a reconocer al otro; no tanto del énfasis en el yo/nosotros como en el tú/él/vosotros/ellos. En relación con quienes comparten la colectividad, el otro interno, esto implica renunciar a que la singularidad de uno o de una determine el factor diferencial del conjunto. Con relación al otro externo, aceptar que la definición del nosotros requiere no estar sujeto a ninguna forma de dominación implica partir de la renuncia a ejercer esa dominación sobre los demás. Implica, en definitiva, trasladar el principio básico de civilidad al que se ha apelado previamente al ámbito de la democracia en Europa.

Sin embargo, este planteamiento abstracto adquiere especial relevancia cuando trasladamos la perspectiva normativa del reconocimiento mutuo al ámbito de lo político. Es decir, al ámbito jurídico-institucional, tanto respecto a los ciudadanos y ciudadanas (ad-intra o «el otro interno») como con relación a la interacción entre hechos políticos nacionales ${ }^{46}$ (ad-extra o «el otro externo»). Lo principal, en ese sentido, es que la posición dêmoicratica no se centra en exclusiva en una de las dos dimensiones: ciudadanía o hechos políticos nacionales. Más bien, plantea una visión del proyecto de integración europea capaz de articular políticamente la interacción entre la individualidad y las colectividades. Es decir, se trabaja en lo común partiendo

45 Claudia Sternberg et al., The Greco-German..., 2

46 Ander Errasti, «Legitimidad dêmoicratica en el horizonte cosmopolita europeo» en Legitimidad y Acción Política, ed. por Norbert Bilbeny (Barcelona: Editorial Universitat de Barcelona, 2018). 
de la diferencia ${ }^{47}$. La propuesta dêmoicratica reconoce, por tanto, la existencia de una ciudadanía en Europa que desarrolla y participa en redes de interacción transnacional a partir de la experiencia y gestión local de retos comunes $^{48}$. El marco dêmoicratico no se plantea, por tanto, como alternativa a esas ciudadanías (locales, regionales o estatales), sino como el espacio que facilita y dinamiza su participación interactiva en el espacio europeo ${ }^{49}$.

Esta dimensión política del reconocimiento mutuo no parte de una realidad institucional de carácter absoluto ni de una aspiración institucional definida a priori. No parte, por tanto, de asumir que los estados-nación sean sujetos inamovibles de la integración europea. Tampoco considera esencial establecer un marco institucional supranacional (europeo) que suprima los hechos políticos nacionales ${ }^{50}$. Sin embargo, afirmar la existencia de un consenso constitucional europeo que presupone los hechos políticos nacionales, especialmente los estados-nación, tampoco equivale a resignarse a un estatus-quo marcado por la actual distribución de poder y diseño institucional. Por el contrario, la propuesta dêmoicratica se plantea desde la premisa

47 Es importante destacar que la propuesta dêmoicratica no pretende plantear una enmienda a la totalidad del actual diseño institucional del proyecto europeo, más bien al contrario: se reconoce que la existencia del Parlamento Europeo (con su aspiración de representar la igualdad entre la ciudadanía europea) y el Consejo (haciendo lo ropio con los hechos nacionales), así como del Tribunal de Luxemburgo como garante de la justicia supra y transnacional, incorporan el potencial dêmoicratico de reconocimiento mutuo y no-dominación. La propuesta, dêmoicratica, por el contrario, afirma que ese potencial dista de haberse alcanzado precisamente porque (1) las perspectivas desde las que se plantea el debate no tienen estos principios en el eje de sus razonamientos y (2) ponen todo el énfasis en planos institucionales (nacional o supranacional) excluyentes, limitando una interacción que en la práctica de la democracia en Europa es más dinámica y compleja (para este debate véase, por ejemplo, Michael Keating, Rescaling the European State. The Making of Territory and the Rise of the Meso (Oxford: Oxford University Press, 2013).

48 Saskia Sassen, The Global City: New York, London, Tokyo (Princeton: Princeton University Press, 1991), Saskia Sassen, Losing Control? Sovereignty in the Age of Globalization, (New York: Columbia University Press, 1996), Ulrich Beck, The Metamorphosis of the World (Cambridge: Polity, 2016), Daniel Innerarity y Ander Errasti, «Cosmopolitan Public Space(s)» en Routledge International Handbook of Cosmopolitanism Studies, ed. por Gerard Delanty (New York: Routledge, 2019, segunda edición)

49 Kalypso Nicolaïdis, «Braving the Waves? Europe's Constitutional Settlement at Twenty» JCMS: Journal of Common Market Studies (2018) 15

50 A día de hoy, estados-nación, si bien una revisión de la teoría de la dêmoicracia a partir de la definición de «hecho político nacional» según expresada por Cheneval y Nicolaïdis sería compatible con una concepción más radical que abarcara la pluralidad de demos que incluyera hechos políticos nacionales sub-estatales (como podrían ser Euskal Herria, Catalunya, Escocia o Flandes, independientemente de si están o no constituidos en estados). En la medida en que no condiciona directamente el argumento (aunque la hipótesis es que lo reforzaría), esta no es la consideración prioritaria de este artículo y queda para postergada para un futuro análisis. 
de que partir de la realidad como es (y no como nos gustaría que fuera) no pasa por resignarse al estatus quo, sino por identificar el aspecto relevante de esa realidad como paso previo a proponer vías para transformarla. En el espacio europeo, el elemento que se presenta como característico tanto de la aspiración política de un proyecto común como de las barreras para materializarlo con éxito no es otro que su diversidad. En concreto, su diversidad de demoi, de pluralidad de demos. Especialmente de demoi nacionales. No en vano, el lema que sintetiza el ethos de la construcción de un proyecto común no es otro que «unidos en la diversidad». Siendo así, ¿qué hay de relevante en la diversidad cuando se plantea que el proyecto de integración debe preservarlo?

La propuesta dêmoicratica parte de la idea de que la democracia debe organizarse en más de una unidad política para poder satisfacer el pluralismo intrínseco a cualquier espacio político. Así, la propuesta dêmoicrática aspira a superar toda tentación de plena soberanía y posibilitar la legitimidad más allá del estado-nación a través de cierta flexibilidad con relación a la definición, adjudicación y ejecución de competencias en sistemas políticos fragmentados ${ }^{51}$ (o compuestos ${ }^{52}$ ) como sería el espacio europeo. Es decir, plantea un modelo capaz de superar la supuesta dicotomía entre fuerzas egoístas (nacionalistas) y actores que se mueven por la razón y la unidad supranacional (europeos). Supera, así, la falsa dicotomía entre plena soberanía estatal (soberanismo) y plena cesión de soberanía (federalismo tradicional).

La propuesta soberanista tiende a identificar esa diversidad con una diversidad de estados-nación soberanos. De este modo, la fórmula que de acuerdo con los soberanistas permite preservar la diversidad a la par que promueve la unión, no es otra que la que pone el eje de la integración en la soberanía estatal. Considera, por tanto, que la diversidad es algo que requiere de compartimentos estancos donde se ejerce la soberanía (el modelo de estados-nación contenedor ${ }^{53}$ ). La alternativa federal tradicional (la propuesta dêmoicratica no deja de ser, en muchos aspectos, una versión de ese planteamiento ${ }^{54}$ ), por el contrario, continúa anclada en el marco conceptual del estado-nación. Así, tiende a concebir la diversidad como una descentra-

51 Kalypso Nicolaïdis, «Conclusion: the federal vision beyond the federal state» en The federal vision: Legitimacy and levels of governance in the United States and the European Union, ed. por Kalypso Nicolaïdis y Robert Howse (Oxford: Oxford University Press, 2001) 442

52 Sergio Fabrini, Which European Union? Europe after the Euro Crisis, (Cambridge: Cambridge University Press, 2015) 213

${ }^{53}$ Ulrich Beck, La sociedad del riesgo global (Madrid: Siglo XXI de España Editores, 1999).

${ }^{54}$ Joseph Lacey, Centripetal..., 86-87 
lización administrativa combinada con una concepción folclórica del pluralismo, en el mejor de los casos, o estrictamente individualizad, en el peor. De este modo, el fin pretendidamente superior de la unión lleva a vaciar de contenido político todo lo relativo a la diversidad, dando paso a la dominación y consiguiente homogeneización. El ejemplo más específico de esa aspiración federal tradicional lo constituye el fallido intento de constitución europea, con su énfasis en cuestiones identitarias (como la historia común europea) y su foco en aspectos de carácter estatalista (como el himno o la bandera $)^{55}$. En la posición soberanista, la ciudadanía se corresponde con la nacionalidad con carácter excluyente, siendo la dimensión europea un mero espacio administrativo de optimización de intereses particulares. En el caso del federalismo tradicional, la nacionalidad se reduce a una cuestión meramente cultural, siendo la ciudadanía un constructo abstracto constituido sobre sujetos atomizados. En ambos casos, el leitmotiv del reconocimiento mutuo queda diluido. Es decir, se ignora que lo relevante del ethos «unidos en la diversidad» no puede definirse de forma autárquica en el espacio nacional ni en el espacio supranacional.

Frente a estos planteamientos, la alternativa dêmoicratica ${ }^{56}$ concibe la Unión Europea como una unión tanto de hechos políticos nacionales como de ciudadanos que gobiernan unidos, pero no son una unidad. Niega, por tanto, la existencia de demos exclusivos (o los demos nacionales, o el demos europeo) y reivindica una pluralidad de demos, un demoi, que en su afán de reconocimiento mutuo (para evitar los riesgos ya conocidos de no hacerlo así como para crear las condiciones necesarias para afrontar retos comunes) están en permanente proceso de transformación. Es decir, por un lado, el modelo dêmoicratico reconoce la importancia de la conciencia nacional como mecanismo para combatir proyectos hegemónicos que vulnerarían el principio de no-dominación inherente al reconocimiento mutuo. Prueba de ello sería que, aún defendiendo la necesidad de que el reconocimiento mutuo lleve a la cesión de soberanía a espacios comunes, mantiene la necesidad de que existan cláusulas (como el artículo 50) que salvaguarden, como recurso último, la soberanía de los hechos políticos naciona$\operatorname{les}^{57}$. Por otro, mientras reconoce esta importancia de los hechos políticos nacionales diferenciados ${ }^{58}$, busca un equilibrio ${ }^{59}$ entre ese reconocimiento y la existencia de un proceso de construcción política europea en constante

55 Kalypso Nicolaïdis, «Braving the...», 8

56 Nicolaïdis (2012) p.3

57 Kalypso Nicolaïdis, «Braving the...», 9

58 Nicolaïdis (2012) p.4

59 Kalypso Nicolaïdis, «European demoicracy and its crisis», JCMS: Journal of Common Market Studies 51, 2 (2013) 352 
transformación ${ }^{60}$. Además, si bien considera implausible e indeseable ${ }^{61}$ la existencia de un demos único europeo ${ }^{62}$, separa esta afirmación de la posibilidad de construir una democracia en Europa ${ }^{63}$.

En definitiva, la propuesta de una Europa dêmoicratica sostiene una posición pragmática que se alinea de lleno con la pretensión normativa de construir un espacio europeo que vele por determinados valores cosmopolitas (justicia más allá de las fronteras domésticas, consolidación de una democracia transnacional, protección subsidiaria de derechos fundamentales, gestión intercultural de la diversidad, respeto a la autodeterminación de los pueblos, etc.) reconociendo, a su vez, que esa pretensión no sólo no ha de ser incompatible con la realidad empírica de los hechos políticos nacionales, sino que tratar de forzarla puede ser tan improductivo como contraproducente. El caso reciente paradigmático sería el de la Unión Monetaria (UM), donde la imposición de un modelo europeo en casos en los que las reformas necesarias podían haberse planteado y ejecutado en el ámbito de los hechos políticos nacionales, ha generado tensiones y complicaciones perfectamente evitables ${ }^{64}$. Así, en lugar de poner el foco en lo verdaderamente relevante (incrementar la eficacia del sistema bancario unificado, evitar desequilibrios unilaterales, en el caso de la UM), se ha asumido que lo prioritario era incrementar la centralización. Es decir, se ha antepuesto el medio al fin que se perseguía, obviando los problemas que la implementación de ese medio podría generar para el fin perseguido. Lo mismo sucede, a la inversa, cuando los hechos políticos nacionales pasan a defender la soberanía como un fin en sí mismo, obviando que aquellos fines que tratan de proteger reivindicando su soberanía pueden ser perfectamente salvaguardados en sistemas de decisión compartida o delegada (siendo paradigmática la defensa de los derechos fundamentales o la gestión de la crisis migratoria ${ }^{65}$ ).

60 Joseph Lacey, Centripetal..., 83

${ }^{61}$ Kalypso Nicolaïdis, «European demoicracy and...» 353

62 Joseph Lacey, Centripetal..., 92

${ }^{63} \mathrm{Si}$ bien no es el punto de debate del artículo, es importante destacar que la calificación de la existencia de un demos europeo está sujeta, en buena medida, a la definición de demos que utilicemos. En ese sentido, si bien la versión más común de la dêmoicracia sostiene que Europa no constituye un demos, hay planteamientos como el de Joseph Lacey, por ejemplo, que definen el demos de tal manera (Joseph Lacey, Centripetal..., 93) que se refieren a la existencia de un fino demos europeo que interactúa con el demos nacional más sólido del dêmoi europeo [Joseph Lacey, Centripetal..., 85]. En cualquier caso, a efectos del artículo esta discusión - que se puede abordar también, en profundidad, en la reflexión de José Luis Martí «European Democracy and the No-Demos Thesis», en Daniel Innerarity et al., New Narrative for a New Europe (London: Rowman \& Littlefield International, 2018) - se restringe más al ámbito conceptual que descriptivo o normativo.

${ }^{64}$ Kalypso Nicolaïdis, «Braving the...», 11

65 Kalypso Nicolaïdis et al. «Just boundaries...» 
Ahí reside, precisamente, el motivo por el cual la respuesta dêmoicratica constituye el prisma analítico más sólido para idear un marco legislativo e institucional capaz de revertir la crisis de la democracia en la que estamos sumidos en Europa. Lo verdaderamente relevante no es la democracia europea, en tanto que perspectiva que lleva a la ciudadanía a evaluar el proyecto de la Unión Europea en términos estatalistas, sino la democracia en Europa. Si aceptamos esta premisa, concluiremos que el modelo dêmoicratico, con su énfasis en la idea de soberanías populares (entendida como la agregación procedimental de voluntades de los múltiples seres humanos a los que se les ha conferido el estatus de ciudadanía ${ }^{66}$ ), ofrece una perspectiva empíricamente más viable y normativamente más sólida para dar respuesta a las causas que han generado el precariado político.

Las causas de ese precariado político, como hemos planteado, no se circunscriben a la esfera nacional, con lo que la respuesta conjunta es ineludible. Sin embargo, esto genera la tentación de pensar lo común en términos de «más Europa» que resulta políticamente inviable. La experiencia de ese precariado, en cambio, se produce en el espacio nacional, generando la tentación opuesta de «menos Europa». La alternativa dêmoicratica rompe con esa falsa dicotomía. Reconoce que el auge del precariado político y su impacto en el sistema político es un problema común - especialmente por su vínculo con una desigualdad que crece en toda Europa - que, sin embargo, puede resolverse desde los hechos políticos nacionales. La intersubjetividad europea no se plantea, por tanto, como incompatible con la intersubjetividad nacional ${ }^{67}$ : la una presupone a la otra. La soberanía compartida implica, en suma, consensuar mecanismos comunes de control de la soberanía de los hechos nacionales, incluyendo la habilidad de las instituciones comunes de revocar la soberanía popular ${ }^{68}$, sin que por ello los hechos nacionales que forman la UE renuncien a su autonomía.

\section{Conclusión}

La clave de la propuesta dêmoicratica reside, en suma, en el equilibrio entre el foco realista en la ciudadanía como motor de interacción y la relevancia de los hechos políticos nacionales como espacios de politización prioritaria de esa ciudadanía, por un lado, y el impulso normativo para combinar estos elementos con la construcción de un proyecto de apertura a lo común y rendición transnacional de cuentas horizontal, por otro. Un pro-

66 Francis Cheneval et al., «The social construction of...», 245

67 Francis Cheneval et al., «The social construction of...», 238

68 Francis Cheneval et al., «The social construction of...», 244 
yecto que no pretende eliminar en un sentido (soberanista) u otro (federal tradicional) el marco institucional vigente, sino desarrollar todo su potencial dêmoicratico.

El énfasis en la dimensión política, instrumental, pragmática, frente a posiciones esencialistas o apriorísticas, incrementa la posibilidad de revertir la crisis de la democracia en dos sentidos. En primer lugar, porque en su énfasis en el componente popular de la soberanía sitúa el principio de igualdad política en el centro del proyecto europeo. La soberanía popular únicamente es operativa si toda la ciudadanía tiene la posibilidad de participar de ella en igualdad de condiciones formales, informales y fácticas. En segundo lugar, porque al concebir el marco institucional, en todos sus niveles, como herramienta imprescindible para canalizar de forma ordenada esa soberanía popular (o soberanías populares), el proyecto dêmoicratico incorpora desde la base la dimensión inclusiva de la democracia. Al no negar ni absolutizar ninguna dimensión del marco institucional, en la medida en que todos responden a distintas expresiones de soberanía popular, pero considerar que todos ellos constituyen el espacio dêmoicratico europeo, se sientan las bases para una gestión inclusiva de las interdependencias.

En definitiva, todo apunta a que desde este prisma dêmoicratico se puede abordar la principal causa del precariado político - el incremento de las desigualdades - sin relegar a una parte de la ciudadanía a la marginalidad democrática. Se abre la posibilidad de superar, de este modo, las carencias de la visión soberanista y federal y sus derivadas populista y tecnocrática. La visión soberanista se presenta incapaz de garantizar la inclusión democrática al obviar que la causa (ni, por tanto, su potencial solución) del precariado político no se circunscribe a la esfera de los hechos políticos nacionales sino al espacio de interdependencias europeo. Sin reconocimiento mutuo horizontal, el ejercicio de la soberanía popular se vuelve inefectivo. La visión federal tradicional, a su vez, niega la igualdad política al obviar la función de politización que, con su diversidad de trayectorias de construcción de soberanías populares, ejercen los hechos políticos nacionales. Sin reconocimiento mutuo vertical, el ejercicio de la soberanía popular se vacía de contenido. Así, el planteamiento soberanista tiende a caer en la degradación populista de la soberanía popular, mientras que el planteamiento federal clásico se desliza hacia posiciones más tecnocráticas. La alternativa dêmoicratica ofrece una perspectiva alternativa desde la cual romper con esta falsa dicotomía y buscar construir soluciones tan legítimas como efectivas.

Porque, en conclusión, no está escrito cómo ha de ser la Unión Europea. La teleología esencialista que domina los discursos mayoritarios en favor y en contra del proyecto de integración europea obvian ese elemento de contingencia que caracteriza a todo proyecto político. La propuesta dêmoi- 
cratica, en cambio, incorpora con su énfasis en el reconocimiento mutuo el elemento de imperfección (realista) a partir del cual trabajar en la construcción de lo común (utópico). Desplaza el marco discursivo naciones sí/no y Europa sí/no, asumiendo que Europa sí y hechos políticos nacionales también. Porque lo que nos hace europeos no es nuestra identidad compartida subjetiva, ni siquiera la aspiración de una ciudadanía común. Lo que nos hace europeos es que, al reunirnos a pensar soluciones para el cambio climático en Barcelona, Leiden, Lodz o Edimburgo, constatamos que participamos en la misma conversación.

\section{Bibliografía}

Albrow, Martin. The Global Age. Cambridge: Blackwell Publishers Polity Press, 1996.

Anderson, Benedict. Imagined Communities: Reflections On the Origin and Spread of Nationalism. London; New York: Verso, 2006.

Bauböck, Rainer. «Democratic inclusion: a pluralist theory of citizenship», en Democratic Inclusion in Dialogue, editado por David Owen. Manchester: Manchester University Press, 2018.

Beck, Ulrich. ¿Qué es la globalización? Falacias del globalismo, respuestas a la globalización. Barcelona: Paidós, 1997.

Beck, Ulrich. Cosmopolitan Vision. Cambridge: Polity Press, 2006.

Beck, Ulrich. La sociedad del riesgo global. Madrid: Siglo XXI de España Editores, 1999.

Beck, Ulrich. The Metamorphosis of the World. Cambridge: Polity, 2016.

Bejan, Theresa. «Difference without Disagreement: Rethinking Hobbes on "Independency" and "Toleration"», The Review of Politics 78 (2016).

Bejan, Theresa. «Evangelical Toleration», The Journal of Politics 77,4 (2015).

Bejan, Theresa. «The Bond of Civility: Roger Williams on toleration and its limits», History of European Ideas 37, 4 (2011).

Bellamy, Richard. «The inevitability of a democratic deficit», en Key Controversies in European Integration, editado por Hubert Zimmermann y Andreas Dür. New York: Palgrave, 2012.

Bengoetxea, Joxerramon. «The current European Crises: the end of pluralism?», en The future of Europe: democracy, legitimacy and justice after the euro crisis, editado por Serge Champeau, Carlos Closa, Daniel Innerarity y Miguel P. Maduro. London: Rowman \& Littlefield International, 2104.

Berlin, Isaiah. Concepts and Categories, editado por Henry Hardy. Princeton: Princeton University Press, 1999.

Billig, Michael. Banal Nationalism. London: SAGE Publications, 1995.

Bullain, Iñigo. «El proceso de oligarquización europeo. De la utopía federal a una distopía social y democrática». Cuadernos Europeos de Deusto 54 (2016).

Bullain, Iñigo. «Europaren Distopia Globalizazio Oligarkikoan». Europa Krisiz Krisi: korapiloa askatzen / Europa en crisis: análisis y propuestas. EuroBasque, 2018. 
Cagiao y Conde, Jorge. Micronacionalismos: ¿No seremos todos nacionalistas? Madrid: Catarata, 2018.

Calhoun, Craig. Nations Matter: Culture, History and the Cosmopolitan Dream. Oxon; New York: Routledge, 2007.

Caney, Simon. Justice Beyond the Borders. Oxford: Oxford University Press, 2005.

Cheneval, Francis y Nicolaïdis, Kalypso. «The social construction of demoicracy in the European Union», European Journal of Political Theory 16, 2 (2017).

Errasti, Ander. «Legitimidad dêmoicratica en el horizonte cosmopolita europeo» en Legitimidad y Acción Política, editado por Norbert Bilbeny. Barcelona: Editorial Universitat de Barcelona, 2018.

Fabbrini, Sergio. Which European Union? Europe after the Euro Crisis. Cambridge: Cambridge University Press, 2015.

Fernández-Albertos, José. Antisistema: Desigualdad Económica y Precariado Político. Madrid: Catarata, 2018.

Fukuyama, Francis. The End of History and the Last Man. New York: Free Press, 1992.

Gagnon, Alain. The Case for Multinational Federalism: Beyond the allencompassing nation. London. Routledge, 2009.

Goikoetxea, Jule. Privatizing Democracy: Global Ideals, European Politics and Basque Territories. Bern, Switzerland: Peter Lang UK, 2017.

Gutiérrez-Peris, Dídac. «Nuevo realineamiento del miedo en Francia y en Europa», Cuadernos Europeos de Deusto 59, editado por Cristina Astier y Ander Errasti (2018).

Hale, Thomas and Held, David. Beyond the Gridlock. New York: Polity Press, 2017.

Iglesias, Marisa. «Las causas de indeterminación del Derecho: una aproximación filosófica», Cuadernos de derecho público 28 (2006).

Innerarity, Daniel y Errasti, Ander. «Cosmopolitan Public Space(s)» en Routledge International Handbook of Cosmopolitanism Studies, editado por Delanty, Gerard. New York: Routledge, 2019, segunda edición.

Innerarity, Daniel, White, Jonathan, Astier, Cristina y Errasti, Ander, editores, New Narrative for a New Europe. London: Rowman \& Littlefield International, 2018.

Innerarity, Daniel. «Transnational Self-determination. Resetting Self-Government in the Age of Interdependence», JCMS: Journal of Common Market Studies, 53 (2015).

Innerarity, Daniel. La Democracia en Europa. Barcelona: Galaxia Gutenberg, 2017.

Innerarity, Daniel. La Política en Tiempos de Indignación. Barcelona: Galaxia Gutenberg: 2015.

Keating, Michael. «Brexit and the Territorial Constitution of the United Kingdom», Droit et société 98, 1 (2018).

Keating, Michael. Plurinational Democracy on a Post-Sovereignty Era. Oxford: Oxford University Press, 2002.

Keating, Michael. Rescaling the European State. The Making of Territory and the Rise of the Meso. Oxford: Oxford University Press, 2013. 
Lacey, Joseph. Centripetal Democracy: Democratic Legitimacy and Political Identity in Belgium, Switzerland, and the European Union. Oxford: Oxford University Press, 2017.

Levitsky, Steven y Ziblatt, Daniel. Cómo mueren las democracias. Barcelona: Ariel, 2018.

Locke, John. Two Treaties of Government, editado por Peter Laslett. Cambridge: Cambridge University Press, 1988.

Luis Martí, José. «European Democracy and the No-Demos Thesis», en Daniel Innerarity et al., New Narrative for a New Europe. London: Rowman \& Littlefield International, 2018.

Milanovic, Branko. Global Inequality: A New Approach for the Age of Globalization. Cambridge: Harvard University Press, 2016.

Näsström, Sofia. «Normative Power of Political Equality», en Political Equality in Transnational Democracy, editado por Eva Erman y Sofia Näsström. New York: Palgrave McMillan, 2013.

Nicolaïdis, Kalypso y Viehoff, Juri. «Just boundaries for demoicrats», Journal of European Integration 39:5 (2017).

Nicolaïdis, Kalypso, Sèbe, Berny y Maas, Gabrielle, editoras. Echoes of Empire: Memory, Identity and Colonial Legacies. London: I. B. Tauris, 2015.

Nicolaïdis, Kalypso. «Braving the Waves? Europe's Constitutional Settlement at Twenty» JCMS: Journal of Common Market Studies (2018).

Nicolaïdis, Kalypso. «Conclusion: the federal vision beyond the federal state» en The federal vision: Legitimacy and levels of governance in the United States and the European Union, editado por Kalypso Nicolaïdis y Robert Howse. Oxford: Oxford University Press, 2001.

Nicolaïdis, Kalypso. «European demoicracy and its crisis», JCMS: Journal of Common Market Studies 51, 2 (2013).

Piketty, Thomas. Capital in the Twenty-First Century. Cambridge: Harvard University Press, 2014.

Sassen, Saskia. Losing Control? Sovereignty in the Age of Globalization. New York: Columbia University Press, 1996.

Sassen, Saskia. The Global City: New York, London, Tokyo. Princeton: Princeton University Press, 1991.

Sternberg, Claudia, Nicolaïdis, Kalypso y Gartzou-Katsouyanni, Kira. The GrecoGerman Affair in the Euro Crisis: Mutual Recognition Lost? London: Palgrave, 2018.

Vallespín, Fernando y Bascuñán, Máriam M. Populismos. Madrid: Alianza Editorial, 2017.

Young, Richard. The Puzzle of Non-Western Democracy. Washington: Carnegie Endowment for International Peace, 2015. 


\section{Sobre el autor}

Ander Errasti es Doctor en Humanidades -Ética y Filosofía Política - en la Universitat Pompeu Fabra (UPF), supervisado por los doctores Sonia Arribas y Daniel Innerarity. Su investigación e centró en un análisis normativo del Cosmopolitismo de Ulrich Beck (Nations and $\mathrm{Na}$ tionalism in a Cosmopolitanized World: Some Lessons from Ulrich Beck's Work). Fue estudiante de doctorado visitante en el Departamento de Políticas y Relaciones Internacionales de la Universidad de Oxford, supervisado por Kalypso Nicolaïdis. Licenciado en Filosofía por la Universitat de Barcelona (UB), MA in Political Philosophy por la UPF, Diplomado en Ciencias Empresariales por la UB, Máster Avanzado en Ciencias Jurídicas por la UPF.

En la actualidad es Policy Leader Fellow de la School of Transnational Governance del Instituto Europeo de Florencia (enero-julio 2019). Asimismo, es profesor ayudante docente en la Universitat Oberta de Catalunya. Desde el 2013 es investigador en el Instituto de Gobernanza Democrática de Donostia - San Sebastián (Globernance), donde ha organizado diversos congresos internacionales, publicaciones y actividades de investigación. En el curso 2017-2018 desarrolló un proyecto de investigación en la Universidad de Edimburgo (supervisado por los profesores Michael Keating y Nicola McEwan) sobre el impacto del Brexit y el referéndum de independencia del 2014 en las instituciones de autogobierno escocesas.

Finalmente, también es miembro del grupo GISME de la UB desde el 2010, dirigido por el profesor Javier Tejada. Como miembro ha organizado diversas actividades de difusión científica, incluyendo colaboraciones con el Museo del Prado, la Fundación Española de Ciencia y Tecnología o Jakiunde (la Academia Vasca de Ciencia y Humanidades). Es asistente de la Coordinación del proyecto «CCentre: hacia un envejecimiento Activo y Bienestar centrados en la ciudadanía» (2016-2019), financiado por el EIT Health y coordinado por la profesora Elena Lauroba. Fue el Project Manager del proyecto SIforAGE: Innovación Social para un Envejecimiento Activo y Saludable para un desarrollo económico sostenible (2013-2016) financiado por la Comisión Europea.

\section{About the Author}

Ander Errasti holds a PhD in Humanities - Ethics and Political Philosophy - from UPF, supervised by Dr Sonia Arribas and Dr Daniel Innerarity. His research focused on a normative analysis of Ulrich Beck's Cosmopolitanism ( «Nations and Nationalism in a Cosmopolitanized World: 
Some Lessons from Ulrich Beck’s Work»). He has been a Visiting Doctoral Student at the Department of Politics and International Relations at Oxford University. BA in Philosophy at University of Barcelona (UB), MA in Political Philosophy at the Pompeu Fabra University (UPF), Business Administration Diploma at UB, Advanced LLM in Legal Sciences at the UPF.

He is a Policy Leaders Fellow at the European University Institute's School of Transnational Governance (January - July 2019). Also, he is teaching assistant at the Open University of Catalonia (UOC). Since 2013 he works at the Basque Institute of Democratic Governance, where he has organised several conferences, publications, and research activities. In the 2017-2018 term he worked on a research project in cooperation with the University of Edinburgh (supervised by Professors Michael Keating and Nicola McEwan) on the impact of Brexit and the 2014 independence referendum on Scotland's self-government institutions.

Finally, Errasti is a member of the GISME group at the UB since 2010, directed by Professor Javier Tejada. In that capacity, he has organised several dissemination activities, including collaborations with the Prado Museum, the Spanish Foundation of Science and Technology, or Jakiunde (the Basque Academy of Science and Humanities). He is the Coordinator Assistant of the "CCentre: Towards Citizen Centered Active Ageing and Well Being» project (2016-2019) financed by the EIT Health and Coordinated by Professor Elena Lauroba. He was the Project Manager of the European Commission funded SIforAGE Project on Social Innovation for Active and Healthy Ageing for Sustainable Economic Growth (20132016). 


\section{Derechos de autor}

Los derechos de autor (para la distribución, comunicación pública, reproducción e inclusión en bases de datos de indexación y repositorios institucionales) de esta publicación (Cuadernos Europeos de Deusto, CED) pertenecen a la editorial Universidad de Deusto. El acceso al contenido digital de cualquier número de Cuadernos Europeos de Deusto es gratuito inmediatamente después de su publicación. Los trabajos podrán leerse, descargarse, copiar y difundir en cualquier medio sin fines comerciales y según lo previsto por la ley; sin la previa autorización de la Editorial (Universidad de Deusto) o el autor. Así mismo, los trabajos editados en CED pueden ser publicados con posterioridad en otros medios o revistas, siempre que el autor indique con claridad y en la primera nota a pie de página que el trabajo se publicó por primera vez en CED, con indicación del número, año, páginas y DOI (si procede). Cualquier otro uso de su contenido en cualquier medio o formato, ahora conocido o desarrollado en el futuro, requiere el permiso previo por escrito del titular de los derechos de autor.

\section{Copyright}

Copyright (for distribution, public communication, reproduction and inclusion in indexation databases and institutional repositories) of this publication (Cuadernos Europeos de Deusto, CED) belongs to the publisher University of Deusto. Access to the digital content of any Issue of Cuadernos Europeos de Deusto is free upon its publication. The content can be read, downloaded, copied, and distributed freely in any medium only for non-commercial purposes and in accordance with any applicable copyright legislation, without prior permission from the copyright holder (University of Deusto) or the author. Thus, the content of CED can be subsequently published in other media or journals, as long as the author clearly indicates in the first footnote that the work was published in CED for the first time, indicating the Issue number, year, pages, and DOI (if applicable). Any other use of its content in any medium or format, now known or developed in the future, requires prior written permission of the copyright holder. 